\title{
Localized Silicon Fusion and Eutectic Bonding for MEMS Fabrication and Packaging
}

\author{
Y. T. Cheng, Liwei Lin, Member, IEEE, and Khalil Najafi, Fellow, IEEE
}

\begin{abstract}
Silicon fusion and eutectic bonding processes based on the technique of localized heating have been successfully demonstrated. Phosphorus-doped polysilicon and gold films are applied separately in the silicon-to-glass fusion bonding and silicon-to-gold eutectic bonding experiments. These films are patterned as line-shape resistive heaters with widths of 5 or $7 \mu \mathrm{m}$ for the purpose of heating and bonding. In the experiments, silicon-to-glass fusion bonding and silicon-to-gold eutectic bonding are successfully achieved at temperature above $1000{ }^{\circ} \mathrm{C}$ and $800{ }^{\circ} \mathrm{C}$, respectively, by applying 1-MPa contact pressure. Both bonding processes can achieve bonding strength comparable to the fracture toughness of bulk silicon in less than $5 \mathrm{~min}$. Without using global heating furnaces, localized bonding process is conducted in the common environment of room temperature and atmospheric pressure. Although these processes are accomplished within a confined bonding region and under high temperature, the substrate temperature remains low. This new class of bonding scheme has potential applications for microelectromechanical systems fabrication and packaging that require low-temperature processing at the wafer level, excellent bonding strength, and hermetic sealing characteristics. [467]
\end{abstract}

Index Terms-Heating, MEMS packaging, wafer bonding.

\section{INTRODUCTION}

B ONDING techniques, including fusion, eutectic, and anodic bonding, have been used in integrated circuit (IC) and microelectromechanical (MEMS) manufacturing for many years [1], [2]. Although still an emerging technology, silicon bonding is already producing such commercial devices as pressure sensors and accelerometers. In general, these bonding processes operate under two basic conditions. First, the two bonding surfaces must be flated to have intimate contact for bonding. Second, proper processing temperatures are required to provide the bonding energy. For example, the conventional silicon-to-silicon fusion bonding process takes place at a bonding temperature of above $1000{ }^{\circ} \mathrm{C}$ [3]. Anodic bonding, on the other hand, is performed at a much lower temperature of about $300{ }^{\circ} \mathrm{C}-450{ }^{\circ} \mathrm{C}$ with the assistance of a high electrostatic field [4]. The silicon-gold eutectic state occurs at a

Manuscript received June 30, 1999; revised October 14, 1999. This work was supported by the Defense Advanced Research Projects Agency under Agreement F30602-97-2-0101. The work of L. Lin was supported in part by the National Science Foundation under CAREER Award ECS-9734 421. An earlier version of this paper was presented at the 1998 Solid-State Sensors and Actuators Workshop, Hilton Head, SC. Subject Editor, E. Overmeier.

Y. T. Cheng and K. Najafi are with the Center for Integrated Microsystems, Department of Electrical Engineering and Computer Science, The University of Michigan at Ann Arbor, Ann Arbor, MI 48109-2122 USA (e-mail: ytcheng@engin.umich.edu).

L. Lin is with the Department of Mechanical Engineering, University of California at Berkeley, Berkeley, CA 94720 USA.

Publisher Item Identifier S 1057-7157(00)01749-2. temperature of $363{ }^{\circ} \mathrm{C}$ that is the lowest bonding temperature for the silicon-gold system [5]. Due to the high-temperature requirement, temperature-sensitive materials and integrated circuits will be damaged or degraded during the bonding processes. Therefore, high-temperature bonding processes are not applicable in fabricating or packaging devices where temperature-sensitive materials exist. During the past few years, efforts have been undertaken to find a reliable bonding process that can be conducted at a low temperature. Unfortunately, these new bonding processes depend highly on the bonding material [6], surface treatment [7], and surface flatness [8].

This paper presents a new approach to bonding based on the concept of localized heating. The bonding processes are conducted locally while the whole wafer is maintained at a low temperature. In addition, localized heating is able to provide high temperature and cause softening of the bonding material in order to alleviate the surface roughness problem. As such, this new technique has potential application to the fabrication and packaging of MEMS microstructures. The following two types of localized bonding processes have been investigated: 1) silicon-to-glass fusion bonding and 2) silicon-to-gold eutectic bonding. Technical issues in bonding conditions, strength, and procedures are discussed. It is our belief that this technique can greatly simplify MEMS fabrication and packaging at both the chip and wafer levels.

\section{Principle of Localized Heating AND Bonding}

Localized heating is provided by using microheaters instead of global heating furnaces. These microheaters are constructed in a way that heating is restricted in a small region that is surrounded by insulation materials. The effectiveness of localized heating depends on the selection of materials and the design of the geometrical shape of the overall structure. For example, a recent heat transfer study [9] has shown that a high temperature of $1000^{\circ} \mathrm{C}$ can be created by using microheaters, while the temperature at neighboring area drops to $100{ }^{\circ} \mathrm{C}$ in less than $2 \mu \mathrm{m}$ away from the microheater [9].

Based on the principle of localized heating, microheaters have been built and subject to bonding experiments, as illustrated in Fig. 1(a). The cross-sectional view shows a cap substrate, which can be made of either silicon or glass, is to be bonded to the device substrate. A silicon-dioxide layer $1 \mu \mathrm{m}$ in thickness is grown on the device substrate for electrical and thermal insulation. In the fusion bonding experiments, polysilicon is deposited and patterned as the heating and bonding material. In the eutectic bonding tests, gold resistive heaters are sputtered and used as the heating and bonding 


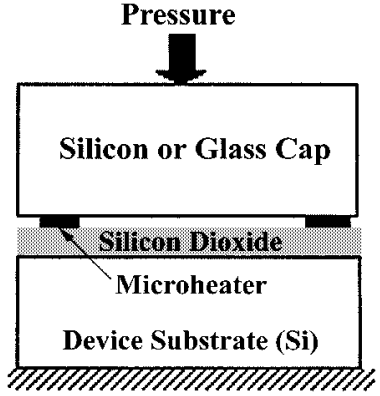

(a)

\section{Pyrex 7740 Glass}

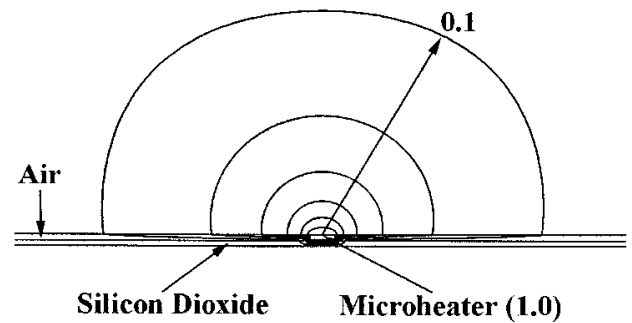

Silicon

b)

Fig. 1. Principle of the localized bonding experiments. (a) Cross-sectional view. (b) Isotherms around a 5- $\mu \mathrm{m}$-wide microheater capped with a Pyrex glass substrate.

material. When an electrical current is applied, the temperature of the microheater rises to activate the bonding process. A heat transfer simulation is shown in Fig. 1(b) illustrating the isotherms of the silicon-to-glass bonding process.

Fig. 2 shows the schematic diagram of the experimental setup. A bonding stage made of stainless steel is designed and machined in-house. The contact pressure is applied by the force screw via a force plate and supporting springs. A force sensor is used to measure the contact pressure such that a proper pressure (about $1 \mathrm{MPa}$ ) is applied on the force plate. When the applied pressure is less than $1 \mathrm{MPa}$, intimate contact becomes a problem such that those bonding tests are not successful. The bonding pressure of $1 \mathrm{MPa}$ is the minimum pressure required for this localized bonding process. An observation hole is drilled such that the bonding process can be monitored under an optical microscope. The enlarged view on the left-hand side shows the bonding specimen. Either silicon or a glass cap substrate is put on top of the device substrate. Two electrical contact pads shown in the figure are used for electrical connections. The device area is designed to enclose MEMS structures by the microheater. In order to measure the temperature surrounding the microheater, a temperature sensor made of polysilicon or gold is placed $15 \mu \mathrm{m}$ away from the bonding area that is not shown in these figures. The temperature of the microheater and temperature sensors are characterized by monitoring the change in resistance that can be achieved by dividing $\Delta V$ by the input current.

Two widths, i.e., 5 or $7 \mu \mathrm{m}$, of the microheaters are designed and tested with a square bonding area of $500 \times 500 \mu \mathrm{m}^{2}$. A current, which depends on the design of the microheaters, is passed through the heater to provide the bonding temperature. An electro-thermal model that was previously established based on the conservation of energy [9] was used to estimate the temperature. Fig. 3 shows the simulation results (solid lines) and the experiments (symbols) of polysilicon microheaters under different input currents without the cap substrate. These experimental data are calculated by assuming a linear dependence of resistivity with respect to temperature

$$
\rho(T)=\rho_{o}\left(1+\xi\left(T-T_{o}\right)\right)
$$

where $\rho_{o}$ is the resistivity at room temperature and $\xi$ is the temperature coefficient of resistivity. For N-type polysilicon with dopant concentration of $7.5 \times 10^{19} / \mathrm{cm}^{3}$, this temperature coefficient is about $1.2 \times 10^{-3} / \mathrm{K}$ [10], [11].

The same principle is used in the temperature sensor to determine the temperature changes at a short distance, i.e., $15 \mu \mathrm{m}$, away from the microheater. It is found that when an electric current of $30 \mathrm{~mA}$ is passed through the 5 - $\mu \mathrm{m}$-wide polysilicon resistive heater, the temperature reaches the melting point of polysilicon $\left(\sim 1415^{\circ} \mathrm{C}\right)$. At the same time, the temperature sensor indicates a temperature increase of less than $40^{\circ} \mathrm{C} 15 \mu \mathrm{m}$ away from the microheater. Apparently, the high-temperature region is well confined in a very small area by using this localized heating scheme.

\section{EXPERIMENTAL RESULTS}

\section{A. Localized Fusion Bonding}

Silicon-to-glass bonding is demonstrated by a Pyrex glass cap substrate (7740, Dow Corning). After placing the glass substrate on top of polysilicon microheaters (on the device substrate), a 31-mA input current is then applied to the 5- $\mu \mathrm{m}$-wide 1.1- $\mu \mathrm{m}$-thick polysilicon microheater for about $5 \mathrm{~min}$. This input current can generate a temperature of about $1300{ }^{\circ} \mathrm{C}$ based on a current-temperature simulation, as shown in Fig. 3 . During the bonding process, the operator can actually see the glow color of microheater by placing the bonding stage under an optical microscope.

Fig. 4 shows the SEM micrograph of the glass substrate after the fusion bond is forcefully broken. It is observed that the square shape microheater is reflected on the originally flat glass substrate. Furthermore, part of the polysilicon was attached to the glass cap. This demonstrates two very important features for the localized fusion bonding experiment. First, the temperature of the microheater can be raised to go over the glass softening point of $820^{\circ} \mathrm{C}$, and soften the glass locally. The structural changes in the glass sometimes cause high stress buildup due to high-temperature gradient. It is found that when a regular glass is used as the packaging cap, cracks can be found at the completion of the bonding process. When a Pyrex glass substrate is used, the cracking phenomenon disappeared. Second, the applied pressure is high enough to cause intimate contact of the glass cap and microheaters. Since intimate contact has been made, a good and reliable fusion bond can be expected under proper temperature and reaction time. 


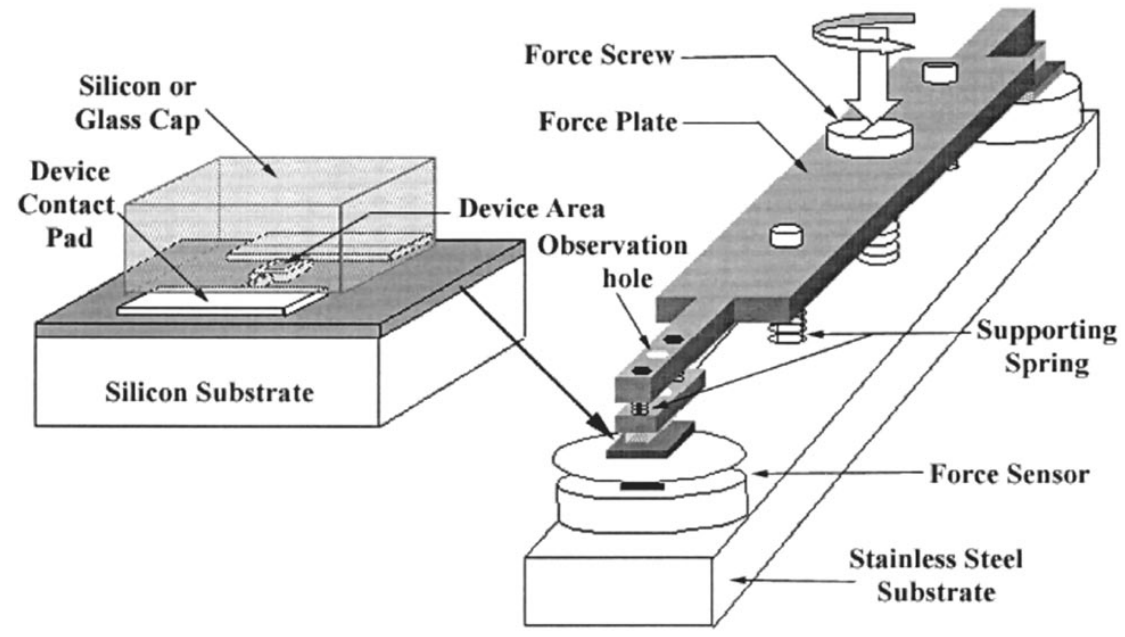

Fig. 2. Schematic of the bonding stage.

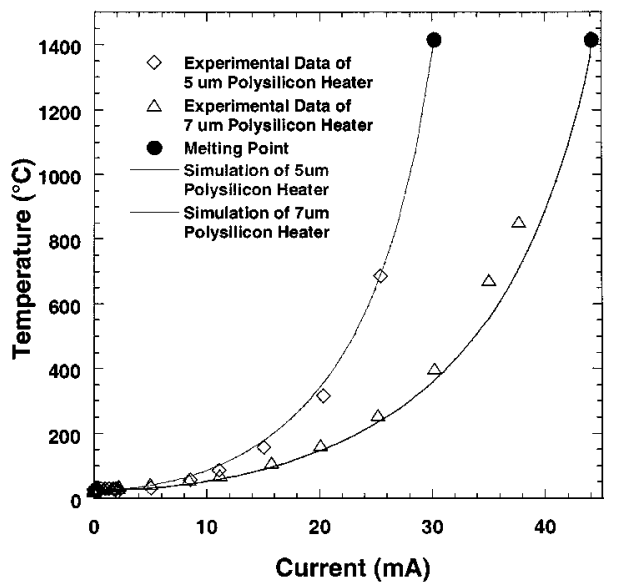

Fig. 3. Experimental and simulation results of 5- and 7- $\mu$ m-wide polysilicon microheaters under different current inputs.

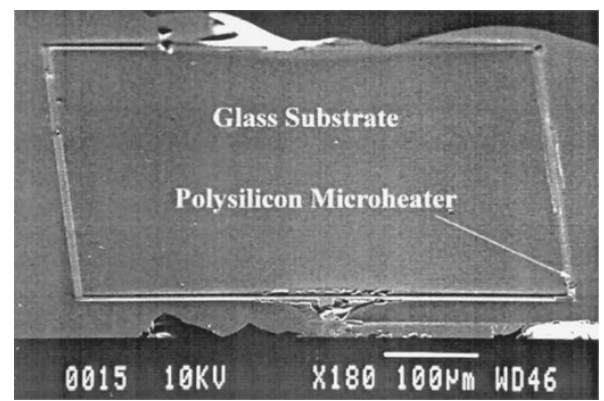

Fig. 4. SEM micrograph showing the glass cap substrate is softened and has the shape of the polysilicon microheater.

In order to determine the bonding strength, a close-up SEM micrograph was taken as shown in Fig. 5. For this particular sample, the breakage was along one of the microheater. Polysilicon heater, silicon dioxide layer and the top glass cap can be clearly identified. The morphology of glass near the microheater is slightly distorted and it indicates that the glass substrate has been locally softened. After dipping into HF solution to remove part of the silicon dioxide, the polysilicon heater is seen delineated in Fig. 6. In this case, the polysilicon-glass bond seems to

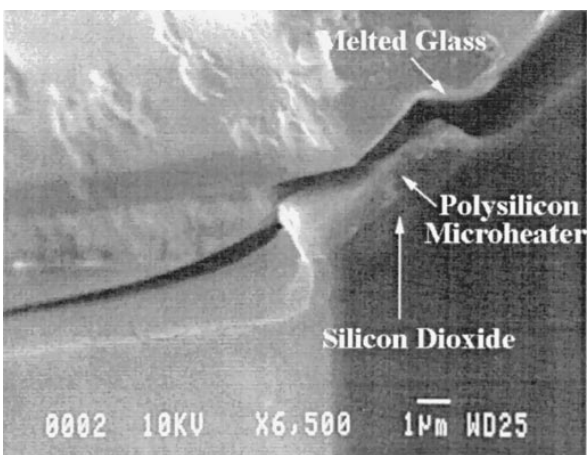

Fig. 5. SEM micrograph shows the localized silicon-glass fusion bonding. After the bond is forcefully broken, microheater, silicon dioxide, and glass cover are clearly observed.

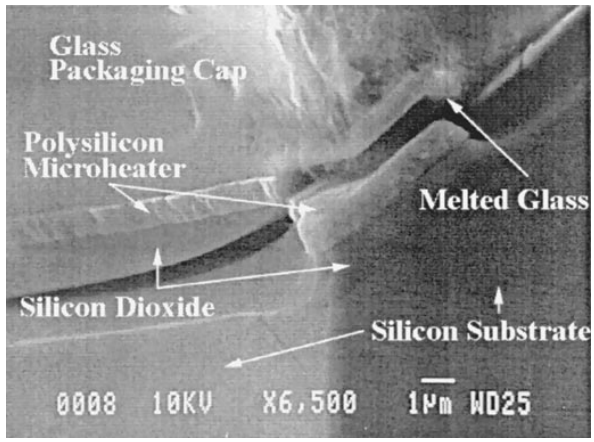

Fig. 6. Polysilicon microheater appears after dipping into HF.

be stronger than the bottom polysilicon-oxide adhesion force as evidenced by the breakage of polysilicon-oxide interface. Therefore, it is suggested that an excellent silicon-to-glass fusion bond is achieved.

According to the fusion bonding principle [12], flat surfaces, hydrophilic surface treatment, sufficient high bonding temperature, and reasonable bonding time will result in successful bonding. The typical bonding procedure is to put the wafers in the conventional oven at above $1000{ }^{\circ} \mathrm{C}$ for about $2 \mathrm{~h}$. In the experiments presented in this paper, microheaters are cleaned by HF dip, sulfuric peroxide mixture (SPM, i.e., a mixture of $\mathrm{H}_{2} \mathrm{SO}_{4}$ and $\mathrm{H}_{2} \mathrm{O}_{2}$ ) cleaning and water rinse to 


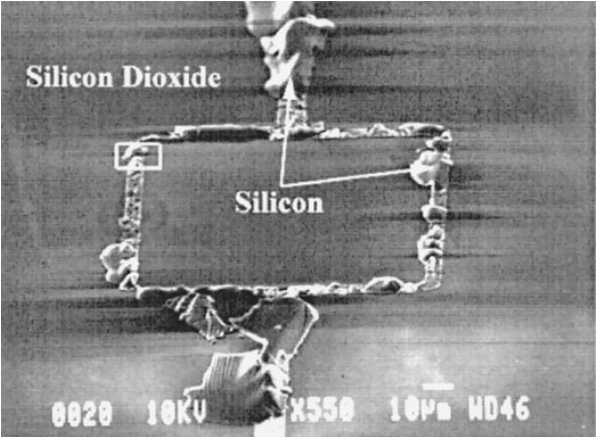

Fig. 7. SEM micrograph showing localized silicon-to-gold eutectic bonding. After the bond is forcefully broken, the silicon cap is torn apart and transferred to the device substrate.

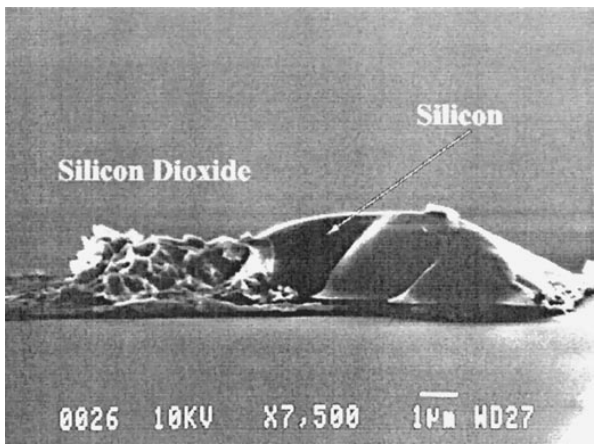

Fig. 8. Close view of SEM micrograph showing the silicon debris attached on the gold microheater after the bond is forcefully broken.

create hydrophilic surface [13]. Intimate contact is accomplished by monitoring the applied force via the force sensor and the bonding temperature is controlled by the theoretical electro-thermal model as well as the experimental resistance measurements. When the microheater is close to the melting temperature of polysilicon, silicon-to-glass fusion bonding can actually occur in less than $2 \mathrm{~min}$. If the bonding temperature is reduced, a longer bonding period is required to achieve excellent bonding strength and uniformity.

\section{B. Localized Eutectic Bonding}

Gold is used in the silicon-to-gold eutectic bonding experiments as both the heating and bonding materials. In these tests, a silicon cap is placed on top of the device substrate with gold microheater. A 0.27-A electrical current is then applied to the 5 - $\mu$-wide $0.5-\mu \mathrm{m}$-thick gold microheater for about 5 $\mathrm{min}$. The bonding temperature is estimated to be about $800{ }^{\circ} \mathrm{C}$ according to both the electrothermal model and experimental measurements of resistivity changes. During the bonding process, gold diffuses into silicon and the resistivity of gold microheater changes. It is necessary to adjust the current density to maintain a high bonding temperature. Fig. 7 shows the result of silicon-to-gold eutectic bond by localized heating. The bond has been forcefully broken and it appears that the silicon substrate was torn apart and attached to the gold microheater. Furthermore, the eutectic bond is uniformly distributed over the boundary of the square-shape microheater.

Fig. 8 is a close-up view of a part of the silicon debris on top of the microheater. The sample is then dipped into gold etchant

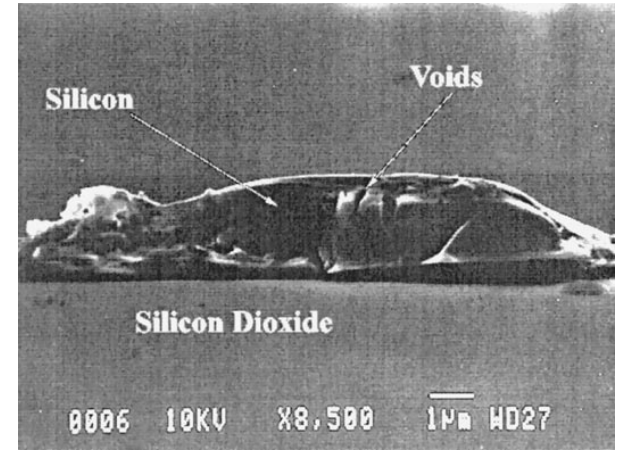

Fig. 9. Close view of SEM micrograph showing voids on the surface of the silicon debris after gold etching.

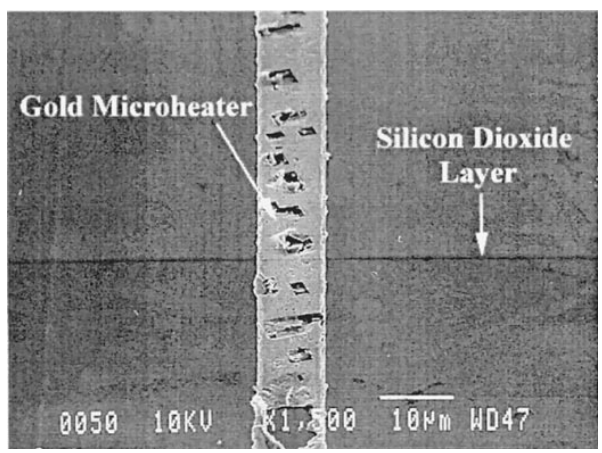

Fig. 10. Nonuniformity is found in a conventional eutectic bonding process.

for $30 \mathrm{~min}$, some voids appear as shown in Fig. 9. Since gold etchant does not attack silicon, these voids are suspected to be the gold-silicon composite alloy. It suggests that gold atoms have diffused into the silicon substrate during the localized eutectic bonding process. The diffusion coefficient of gold in silicon was previously reported as $1.1 \times 10^{-7} \mathrm{~m}^{2} / \mathrm{s}$ [14]. By applying the average length of the voids of $11 \mu \mathrm{m}$ as the diffusion length, the average bonding temperature is calculated to be $750{ }^{\circ} \mathrm{C}$, which is close to our analytical estimation.

A conventional eutectic bonding process is conducted in an oven for the purpose of comparison [5], [15]. The processing temperature is first ramped to $410^{\circ} \mathrm{C}$ in about $10 \mathrm{~min}$ and is kept at $410{ }^{\circ} \mathrm{C}$ for $10 \mathrm{~min}$ before cooling down to a low temperature in another $40 \mathrm{~min}$. The eutectic bond is then forcefully broken as shown in Fig. 10. Nonuniform bonding can be clearly observed in this photo. This is probably the reason that hermetic sealing was not accomplished in a previous report [15]. Since the diffusivity [14] and solubility [16] of gold into silicon substrate increase when the processing temperature increases, a higher temperature is preferred in the eutectic bonding process. Localized eutectic bonding processes as demonstrated in this paper provide a high temperature for more gold atoms to diffuse into silicon. Therefore, a thicker layer of gold-silicon alloy can form [17] and a stronger eutectic bond is expected [18].

\section{DISCUSSION}

Temperature and processing time are the two key factors for both fusion and eutectic bonding if intimate contact has been achieved. In the silicon-to-glass fusion bonding system, atoms obtain thermal energy provided by the high temperature 


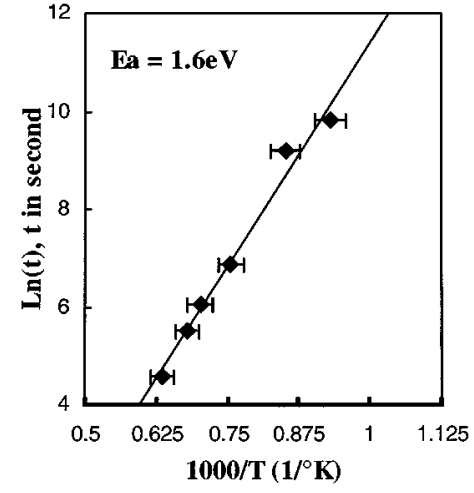

Fig. 11. Experimental result of bonding time versus bonding temperature.

to overcome reaction barrier to form chemical bonds. In the silicon-to-gold eutectic bonding system, atom diffusion is intensively increased under high-temperature environment when atoms overcome the diffusion barrier to form eutectic bond. Therefore, it is desirable to have high processing temperatures in both fusion and eutectic bonding processes for high diffusion constants and reaction rates. Localized heating provides an excellent approach to accomplish the high-temperature requirement while maintaining low temperature at the wafer level. Fast reaction and strong bonding are expected to occur locally. In additions, both bondings can be achieved by applying a 1-MPa contact pressure to ensure intimate contact. This stress is much smaller than the ultimate compressive stress of metal, silicon, and silicon compounds. Therefore, any detrimental effect on the device substrate can be avoided if this scheme is applied for MEMS packaging or fabrication.

By examining the interface of silicon-to-glass fusion bonding, as shown in Fig. 6, it is concluded that the fusion bonding strength can be larger than the fracture strength of thermal oxide and the adhesion force between thermal oxide and silicon substrate. Previously, Li et al. [19] reported that the adhesion force of thermal oxide and silicon is above 13 MPa. Another report by De Reus and Lindahl [20] estimated that when silicon is fractured at the bonding interface, the bonding strength is estimated at about $30 \mathrm{MPa}$. In both cases, the bonding strength is higher than the failure toughness of bulk silicon at approximately $10 \mathrm{MPa}$ [21]. Based on our experimental observation, both silicon-to-glass fusion bond and silicon-to-gold eutectic bond can cause the fracture of silicon when the bond is forcefully broken. Therefore, it is suggested that the bonding strength of localized silicon-to-glass fusion and silicon-to-gold eutectic bond is at least $10 \mathrm{MPa}$.

Localized polysilicon-to-glass fusion bonding is demonstrated for the first time and it is important to characterize the bonding. Fig. 11 shows $\ln (t)$ versus $1000 / T$ plot in an effort to measure the bonding activation energy (Ea), where $t$ is the annealing time leading to a given fracture morphology of bonding interface which is bonded and $T$ is temperature in Kelvin. The experimental result is approximated as Arhennius relationship

$$
\ln (t)=\mathrm{Ea} / K *(1 / T)+C
$$

where $C$ is a constant and $\mathrm{Ea}$ is the activation energy and $K$ is the Boltzmann constant. A value of $1.6 \mathrm{eV}$ for $\mathrm{Ea}$ is extracted from Fig. 11 and this number is close to the number obtained from silicon direct bonding (1.8-2.1 eV) [22], [23]. Interface polymerization reaction involved in silicon dioxide formation has been proposed as the bonding mechanism for these global silicon direct bonding at very high temperature. Since the measured bonding activation energy for localized fusion bonding is close to the reported number, a similar polymerization reaction may occur under localized heating. However, further investigations are required to achieve a full understanding of the mechanisms of localized bonding.

Localized heating can be achieved by other means such as focused laser beams [24] and microwave heating [25]. In addition to the heating sources, the design of insulation layers and the understanding of the localized bonding mechanism also determine the success of the process. This paper presents the foundations for localized heating and bonding as an effort to establish new processes for MEMS packaging and fabrication.

\section{CONCLUSION}

Localized fusion and eutectic bonding processes have been successfully demonstrated in this paper. Phosphorus doped polysilicon and gold resistive heaters are used in the silicon-to-glass fusion and silicon-to-gold eutectic bonding processes, respectively. It is found that both processes can be accomplished in less than 5 min with excellent bonding strength and uniformity. In the silicon-to-glass fusion bonding process, an input current of about $31 \mathrm{~mA}$ is necessary to pass through a $5 \times 1.1 \mu \mathrm{m}^{2}$ microheater to activate the bonding process. In the silicon-to-gold eutectic bonding process, an input current of about $0.27 \mathrm{~A}$ is needed to reach a temperature about $800{ }^{\circ} \mathrm{C}$ for a $5 \times 0.5 \mu \mathrm{m}^{2}$ gold microheater. Based on the experimental observation, the bonding strength of both schemes can reach at least $10 \mathrm{MPa}$. Furthermore, the bonding activation energy for localized silicon-to-glass fusion bond is characterized at $1.6 \mathrm{eV}$. Hermeticity of the seal is one of the main parameters of interest in MEMS device bonding. A dew point sensor was packaged inside the encapsulation area to detect leakage and long-term hermeticity [26] as the continuation of the current work. We believe these techniques can greatly simplify MEMS fabrication and packaging at both the wafer and chip levels.

\section{ACKNOWLEDGMENT}

The authors would like to thank Prof. Nguyen, The University of Michigan at Ann Arbor, for valuable discussions.

\section{REFERENCES}

[1] W. H. Ko, J. T. Suminto, and G. J. Yeh, "Bonding techniques for microsensors," in Micromaching and Micropackaging for Transducers. Amsterdam, The Netherlands: Elsevier, 1985.

[2] P. W. Barth, "Silicon fusion bonding for fabrication of sensors, actuators and microstructures," Sens. Actuators, vol. 23, pp. 919-926, 1990.

[3] C. Harendt, H.-G. Graf, B. Höfflinger, and J. E. Penteker, "Silicon fusion bonding and its characterization," J. Micromech. Microeng., vol. 2, pp. 113-116, 1992.

[4] G. D. Wallis and D. I. Pomerantz, "Field assisted glass-metal sealing," J. Appl. Phys., vol. 40, pp. 3946-3948, 1969. 
[5] L. Valero, "The fundamentals of eutectic die attach," Semicond. Int., vol. 7, pp. 236-241, 1984.

[6] H. Reichl, "Packaging and interconnection of sensors," Sens. Actuators, vol. 25, pp. 63-71, 1990

[7] Q. Y. Tong, G. Cha, R. Gafiteanu, and U. Gösele, "Low temperature wafer direct bonding," J. Microelectromech. Syst., vol. 3, pp. 29-35, Mar. 1994.

[8] B. Ziaie, J. Von Arx, M. Dokmeci, and K. Najafi, "A hermetic glass-silicon micropackages with high density on-chip feedthroughs for sensors and actuators," J. Microelectromech. Syst., vol. 5, pp. 166-179, Sept. 1996.

[9] L. Lin, "Selective encapsulations of MEMS: Micro channels, needles, resonators, and electromechanical filters," Ph.D. dissertation, Dept. Mech. Eng., Univ. California at Berkeley, Berkeley, CA, 1993.

[10] N. C. C. Lu, L. Gerzberg, and J. D. Meindl, "A Quantitative model of the effect of grain sizeon the resistivity of polycrystalline silicon films," IEEE Electron Device Lett., vol. EDL-1, pp. 38-41, Jan. 1980.

[11] J. Y. W. Seto, "The electrical properties of polycrytalline silicon," $J$. Appl. Phys., vol. 46, pp. 5247-5254, 1975.

[12] U. Gösele and Q. Y. Tong, "Semiconductor wafer bonding," Annu. Rev. Mater. Sci., pp. 215-241, 1998.

[13] K. Ljungberg, U. Jansson, S. Bengtsson, and A. Söderbärg, "Modification of silicon surface with $\mathrm{H}_{2} \mathrm{SO}_{4}: \mathrm{H}_{2} \mathrm{O}: \mathrm{HF}$ and $\mathrm{HNO}_{3}: \mathrm{HF}$ for wafer bonding applications," J. Electrochem. Soc., vol. 143, pp. 1709-1714, 1996.

[14] CRC Materias Science and Engineering Handbook. Boca Raton, FL: CRC Press, 1997, p. 255.

[15] M. B. Cohn, Y. Liang, R. Howe, and A. P. Pisano, "Wafer to wafer transfer OF microstructures for vacuum package," in Tech. Dig. Solid State Sensor Actuator Workshop, SC, 1996, pp. 32-35.

[16] H. Okamoto and T. B. Massalaski, Binary Phase Diagram. Materials Park, OH: ASM Int., 1986, p. 312.

[17] P.-H Chang, G. Berman, and C. C. Chen, "Transmission electron microscopy of gold-silicon interactions on the backside of wafers," J. Appl. Phys., vol. 63, pp. 1473-1477, 1988.

[18] A. L. Tiensuu, M. Bexwell, J. Schweitz, L. Smith, and S. Johansson, "Assembling three-dimensional microstructures using gold-silicon eutectic bonding," Sens. Actuators, vol. 45, pp. 227-236, 1994.

[19] H. Li, G. L. Sun, J. Zhan, and Q. Y. Tong, "Some material structural properties of SOI substrates produced by SDB technology," Appl. Surf. Sci., vol. 30, pp. 397-401, 1987.

[20] R. de Reus and M. Lindahl, "Si-to-Si wafer bonding using evaporated glass," in Int. Solid-State Sens. Actuators Transducers'97 Conf., Chicago, IL, pp. 661-664.

[21] R. W. Bower, M. S. Ismail, and B. E. Roberds, "Low temperature $\mathrm{Si}_{3} \mathrm{~N}_{4}$ direct bonding," Appl. Phys. Lett., vol. 62, pp. 3485-3487, 1993.

[22] R. Stengl, T. Tan, and U. Gösele, "A model for the silicon wafer bonding process," Jpn. J. Appl. Phys., vol. 60, pp. 1736-1741, 1989.

[23] W. P. Maszara, G. Goetz, A. Caviglia, and J. B. McKitterick, "Bonding of silicon wafer for silicon-on-insulator," J. Appl. Phys., vol. 64, pp. 4943-4950, 1988.

[24] C. L. Rambin and R. O. Warrington, "Micro-assembly with a focused laser beam," in Proc. IEEE MEMS, 1994, pp. 285-290.

[25] N. K. Budraa, H. W. Jackson, M. Barmatz, W. T. Pike, and J. D. Mai, "Low pressure and low temperature hermetic wafer bonding using microwave heating," in IEEE 12th Int. MEMS Conf., 1999, pp. 490-492.

[26] Y. T. Cheng, L. Lin, and K. Najafi, "Localized bonding with PSG or indium solder as intermediate layer," in IEEE 12th Int. MEMS Conf., 1999, pp. 285-289.
Y. T. Cheng was born in Taiwan, R.O.C. He received the B.S. and M.S. degree from the National Tsing Hua University, Hsinchu, Taiwan, R.O.C., in 1991 and 1993, respectively, the M.S. degree from Carnegie-Mellon University, Pittsburgh, PA, in 1996, and is currently working toward the Ph.D. degree at The University of Michigan at Ann Arbor.

From 1993 to 1995, he served in the R.O.C. Army as a Troop Transportation Officer. His research interests include the fundamental study of materials for MEMS applications, micropackaging, and new hybrid micromachining fabrication of microstructures, microsensors, and microactuators. His current research is developing a vacuum micropackaging technology for micro-resonators, and micro-oscillators in wireless communication system.

Mr. Cheng is a member of Phi Tau Phi.

Liwei Lin (S'92-M'93) received the B.S. degree in power mechanical engineering from National Tsing Hua University, Taiwan, R.O.C., in 1986, and the M.S. and Ph.D. degrees in mechanical engineering from the University of California at Berkeley, in 1991 and 1993, respectively.

From 1993 to 1994, he was with BEI Electronics Inc., where he was involved in research and development of microsensors. From 1994 to 1996, he was an Associate Professor in the Institute of Applied Mechanics, National Taiwan University, Taiwan, R.O.C. From 1996 to 1999, he was an Assistant Professor at the Mechanical Engineering and Applied Mechanics Department, The University of Michigan at Ann Arbor. Since 1999, he has been an Assistant Professor in the Mechanical Engineering Department and Associate Director at the Berkeley Sensor and Actuator Center, University of California at Berkeley. His research interests are in microelectromechanical systems, including design, modeling, and fabrication of microstructures, microsensors, and microactuators. He holds six U.S. patents in the area of MEMS

Dr. Lin was the recipient of the 1998 National Science Foundation CAREER Award for research in MEMS packaging. He led the effort in establishing the MEMS sub-division in ASME and is currently serving as the Vice chairman of the Executive Committee for the MEMS sub-division.

Khalil Najafi (S'84-M'85-SM'97-F'99) was born in 1958. He received the B.S., M.S., and Ph.D. degrees from The University of Michigan at Ann Arbor, in 1980, 1981, and 1986, respectively, all in electrical engineering.

From 1986 to 1988, he was a Research Fellow, from 1988 to 1990, an Assistant Research Scientist, from 1990 to 1993, an Assistant Professor, from 1993 to 1998, an Associate Professor, and since September 1998, a Professor and the Director of the Solid-State Electronics Laboratory, Department of Electrical Engineering and Computer Science, The University of Michigan at Ann Arbor. His research interests include microfabrication and micromachining technologies for solid-state integrated sensors and microactuators, analog and digital integrated circuits, implantable microtelemetry systems and transducers for biomedical applications and wireless communication, technologies and structures for MEMS and microstructures, hermetic packaging techniques for microtransducers, and low-power wireless sensing/actuating systems. He is and editor for Solid-State Sensors and an associate editor for the Journal of Micromechanics and Microengineering.

Dr. Najafi has been active in the field of solid-state sensors and actuators for over 15 years, and has been involved in several conferences and workshops dealing with solid-state sensors and actuators, including the International Conference on Solid-State Sensors and Actuators, the Hilton-Head Solid-State Sensors and Actuators Workshop, and the IEEE/ASME Micro Electromechanical Systems (MEMS) Workshop. He is an editor for the IEEE TRANSACTIONS ON ELECTRON DEVICES. He was awarded a National Science Foundation Young Investigator Award (1992-1997), was the recipient of the Beatrice Winner Award for Editorial Excellence presented at the 1986 International Solid-State Circuits Conference, and the Paul Rappaport Award for co-authoring the Best Paper published in the IEEE TRANSACTIONS ON ELECTRON DEVICES. In 1994, he received The University of Michigan at Ann Arbor's Henry Russel Award for outstanding achievement and scholarship, and was selected by students in the Electrical Engineering and Computer Science Department as the "Professor of the Year" in 1993. In 1998, he was named the Arthur F. Thurnau Professor for outstanding contributions to teaching and research, and received the College of Engineering's Research Excellence Award. 